\title{
The Roles of Betulinic Acid on Circulating Concentrations of Creatine Kinase and Immunomodulation in Mice Infected With Chloroquine-Susceptible and Resistant Strains of Plasmodium Berghei
}

Oludele John Olanlokun ( $\square$ jodel72000@yahoo.com )

University of Ibadan College of Medicine https://orcid.org/0000-0001-8882-1601

Praise Oghenegare Okoro

University of Ibadan College of Medicine

Olufunso Olabode Olorunsogo

University of Ibadan College of Medicine

\section{Research Article}

Keywords: Betulinic acid, Cytokines, Creatine kinase, C-reactive protein, toxicity

Posted Date: February 17th, 2021

DOl: https://doi.org/10.21203/rs.3.rs-202769/v1

License: (c) (1) This work is licensed under a Creative Commons Attribution 4.0 International License.

Read Full License

Version of Record: A version of this preprint was published at Journal of Parasitic Diseases on July 31st, 2021. See the published version at https://doi.org/10.1007/s12639-021-01407-9. 


\section{Abstract}

Complete malarial therapy depends largely on the immunological and inflammatory response of the host to the invading potentials of malarial parasite. In this study, we evaluated the roles of betulinic acid on immunological response, anti-inflammatory potentials and concentrations of creatine kinase in mice infected with chloroquine susceptible (NK 65) and resistant (ANKA) strains of Plasmodium berghei. Serum Interlukins $1 \beta$ and 6 (IL-1 $\beta$, IL-6), tumour necrosis factor alpha (TNFa), immunoglobulins $G$ and $M$ (IgG and IgM), C-reactive protein (CRP) and creatine kinas (CK). Furthermore, liver marker enzymes; aspartate, alanine aminotransferases (AST and ALT, respectively) and gamma glutammyl transferase (GGT) were determined. The results showed that betulinic acid dose dependently decreased IL-1 $\beta$, IL-6, TNFa and CRP relative to the infected control. The IgG and IgM levels significantly increased in both models while CK decreased insignificantly in both models. Serum AST, ALT and GGT significantly decreased compared to the infected control. These results showed that betulinic acid has antiinflammatory, immunomodulatory and mitigating effects on malarial infection in mice. Furthermore, the down-regulatory effect of betulinic acid on CK is indicative of decrease in muscle injury which is a major pathological concern in malarial infection and treatment.

\section{Introduction}

The pathophysiology and lethal effect of human malarial infection has been adjudged to be a consequence of imbalance between the pro- and anti-inflammatory cytokines in the system. Being an infectious disease, malarial infection causes a systemic human disease with clinical and biomedical similarities to other infectious diseases such as bacterial and viral diseases. Furthermore, common symptoms such as loss of appetite, tiredness, aching joints and muscles, fever and sleepiness that patients experience in systemic infection is also common to vivax and falciparum malaria. To protect the cellular contents of the host, malarial infection elicits immune response via the secretion of cytokines by the specific cells of immune system. They are signaling molecules that mediate and regulate inflammation. There are both pro-inflammatory and anti-inflammatory cytokines and some of them are pleiotrophic in functions (Zhang and An 2007). Both inflammatory and immunological response initiation to malarial infection leads to malarial disease symptoms and the initial inflammatory symptoms alleviates infection. However, during infection, leucocytes, lymphocytes, monocytes and phagocytes are activated to secret inflammatory mediators that accelerate detectable parasite infection (Mavondo et al 2019).

Endogenous cytokines such as tumour necrosis factor alpha (TNFa), interlukin 1 beta (IL-1 $\beta$ ) and interlukin 6 (IL-6) are pro-inflammatory cytokines released as a consequential effect to the cytosolic presence of pathogen-associated molecular patterns (PAMPs) such as glycosyl phosphatidyl inositol (GPI) moieties that are attached to the antigens at the exterior portion of malarial parasites or may be found free in solution. The GPI induce elevated levels of TNFa and IL-1 $\beta$ causing increase in body temperature (Schofield, and Hackett 1993; Tachado et al 1996). Apart from the GPI, malarial pigment, otherwise known as hemozoin also raise the levels of the pro-inflammatory cytokines. Malarial 
inflammatory response in the host heralds the onset of the pathophysiology of malaria, thus indicating that malarial treatment should be directed towards parasite clearance and disease. The C-reactive protein (CRP) is a pentameric, ring-shaped protein found in the blood plasma and its circulating concentrations rise in response to inflammation. It is a protein of hepatic origin that increases as a result of IL-6 secretion by macrophages and T cells (Thompson et al 1999). Several cases of skeletal muscle necrosis as a result of malarial infection have been reported (Mishra and Newton 2009; Marrelli and Brotto 2016). There are biomarkers that can link injured skeletal muscles with malarial infection. Significant deviation from the normal serum levels of creatine kinase has been reported in malarial patients with severe muscle injury (Miller et al 1989; Davis et al 2000). Creatine kinase is an enzyme protein, predominantly found in cells of cardiac and skeletal muscles, involved in the synthesis and use of energy providing molecules. Although, chloroquine is used in the treatment of malaria, it has been reported that its prolonged use can cause heart blockage and progressive myopathy (Verlinden et al 2016). Malarial phytotherapy is both antiparasitic and anti-disease. The antiplasmodial activities of phytochemicals such as limonoid (Braga et al 2020), Asiatic acid (Mavondo et al 2016), friedelan-3-one (Noungoue et al 2009) and betulinic acid (Egbubine et al., 2020) have been established. Although, betulinic acid, a plant triterpene has antiplasmodial effects against both chloroquine-sensitive and resistant strains of Plasmodium species, its effects in modulating the activities of inflammatory cytokines, immunoglobulins, creatine kinase and ability to alleviate the toxicity of some antimalarial drugs in different strains of malaria parasites' infection is yet to be reported. It is in this regard, we investigated the modulatory potentials of betulinic acid as an alternative in malarial therapy.

\section{Materials And Methods}

\section{Preparation of betulinic acid}

Betulinic acid was purified from the stem bark of Alstonia boonei and its purity was established by comparing the spectroscopic data $\left({ }^{13} \mathrm{C},{ }^{1} \mathrm{H}, \mathrm{COSY}, \mathrm{HMBC}, \mathrm{HSQC}\right.$ and DEPT) obtained with others previously obtained from other plants and there was similarity in these data. It was thereafter kept in the refrigerator until used.

\section{Experimental animals and infection with parasites and treatment}

Fifty male Swiss mice $(18 \pm 3 \mathrm{~g})$ were obtained from the animal house section of Malarial Unit, Institute of Advanced Medical Research and Training, College of Medicine, University of Ibadan. They were acclimatized for one week, divided into two. Twenty of the first twenty-five were infected with chloroquine sensitive (NK 65) strain of Plasmodium berghei with infected erythrocytes from a donour mouse $\left(10^{7}\right.$ inoculum). Parasitemia was confirmed by microscopy after 72 hours and they were divided into four groups $(n=5)$. Group I is the un-infected animals designated as normal control (treated with $10 \mathrm{ml} / \mathrm{kg}$ distilled water), group II which is the infected control was treated with the vehicle $(10 \mathrm{ml} / \mathrm{kg}$ of $5 \% \mathrm{v} / \mathrm{v}$ DMSO), and group III was treated with standard drug, coartem $(10 \mathrm{mg} / \mathrm{kg})$. Graded doses of betulinic acid $(12.5$ and $25 \mathrm{mg} / \mathrm{kg}$ ) were used to treat groups IV and $\mathrm{V}$. The animals were treated for 7 days and 
parasitemia was determined by microsco.py at two days interval. The research protocol for chloroquine resistant model looked more like the susceptible one except that the animals were infected with infected erythrocytes (ANKA) from a donor mouse, treatment lasted for 5 consecutive days, parasitemia was assessed daily and mefloquine was used as the standard drug (Ryle and Peters, 1970).

\section{Biochemical assays}

\section{Assay of serum IL-1 $\beta$ and IL-6}

ELISA kits for IL-1 $\beta$ and IL-6, obtained from Elabscience, USA were used to assay for serum IL-1 $\beta$ and IL- 6 by strictly following the manufacturer's protocol using DNM-9602A microplate reader.

\section{Determination of tumour necrosis factor alpha and C-reactive protein}

Serum levels of TNFa and CRP were determined by using ELISA assay kits from Elabscience, USA by following the manufacturer's protocol using a microplate reader.

\section{Immunoglobulins (IgG and IgM) assays}

Assays of relevant immunoglobulins (IgG and $\operatorname{lgM}$ ) to malarial study were carried out using mouse immune-turbidimetric assay kits (Fortress Diagnostics, Antrim, UK) by following the manufacturer's assay protocols.

\section{Creatine kinase activity}

Extent of tissue injury in malarial infection and modulatory effect of betulinic acid was assessed via the determination of creatine kinase activity. This was done using ELISA assay kit (Elabscience, USA).

\section{Serum AST, ALT and GGT assay}

Serum aspartate and alanine aminotransferases (AST and ALT, respectively) level were determined by using ELISA assay kits (from MTD diagnostics, Italy), and gamma glutamyl transferase (GGT) levels were determined by using ELISA assay kits (Fortress diagnostics, UK) strictly following the manufacturer's protocol.

\section{Statistical analysis}

Data were analyzed using descriptive statistics on duplicates (mean \pm standard deviation). They were further analyzed by comparing the normal control data with test groups using one-way analysis of variance. Graphpad prism (7.0 version) was used and Dunettes comparison method was used to compare means among columns.

\section{Results}




\section{Betulinic acid modulates IL-1ßand IL-6 in both models of malarial infection}

The influence of betulinic acid on serum IL-1 $\beta$ and IL- 6 in mice infected with chloroquine susceptible and resistant strains of Plasmodium berghei are presented in Fig. 1. We used different models of parasite strain since there is variation in the potency of drugs based on the parasite strain and to see if this would bring about variation in interlukin levels in response to betulinic acid intervention. Our results show that there was a significant $(P<0.0001)$ increase in IL-1 $\beta$ levels in the infected controls of both models (Fig. 1a) compared to the normal control. Although, IL-1 $\beta$ levels in betulinic acid treated mice in both models significantly increased compared with the normal control including the standard drug (coartem) in the susceptible model, $12.5 \mathrm{mg} / \mathrm{kg}$ treatment in the susceptible model significantly decreased IL-1 $\beta$ levels to a level that is not statistically significant from the normal control (Fig. 1b).

It is interesting to note also that, contrary to a decrease in the level of IL-1 $1 \beta$ observed in both susceptible and resistant models, betulinic acid dose-dependently increased IL-6 levels in both models although such increase is not comparable with the normal control. We however, noticed that indeed, administration of betulinic acid caused an increase in the level of IL-6 in mice treated with betulinic acid $(25 \mathrm{mg} / \mathrm{kg})$ significantly $(P<0.001)$ higher than the infected control (Fig. 1d) while there was no such significant difference in the resistant model (Fig. 1c).

\section{Betulinic acid decreases TNFa and CRP inPlasmodium bergheimodels of malaria}

The effect of betulinic acid administration on TNFa and CRP levels in Plasmodium berghei-infected mice is presented in Fig. 2. Malarial infection significantly $(P<0.0001)$ increased TNFa levels in both models as observed in the sera of the mice in the infected control group compared with the normal control (Figs. 2a and 2b). It is however interesting to note that treatment with betulinic acid flattens the curve by significantly decreasing the levels of TNFa in both models. Furthermore, when compared with the standard drug, betulinic acid $(12.5 \mathrm{mg} / \mathrm{kg})$ significantly $(P<0.05)$ decreased TNFa when compared with mefloquine (Fig. 2a). Similar result is obtained in the susceptible model in which betulinic acid $(12.5 \mathrm{mg} / \mathrm{kg})$ significantly $(P<0.05)$ decreased the level of TNFa compared with the standard drug, coartem (Fig. 2b). Serum CRP level in the infected mice that were not treated significantly increased in the resistant $(P<0.05)$ and susceptible $(P<0.01)$ models (Figs. $2 \mathrm{c}$ and $2 \mathrm{~d}$, respectively). In both models, CRP levels in infected animals that were treated with betulinic acid did not vary significantly when compared with the normal control. Although, CRP levels in the mice treated with graded doses of betulinic acid did not vary significantly when compared with the drug control in the resistant model (Fig. 2c), there was a significant $(P<0.01)$ increase in serum CRP level of mice treated with betulinic acid $(12.5 \mathrm{mg} / \mathrm{kg})$ compared with the drug (coartem) control while the $25 \mathrm{mg} / \mathrm{kg}$ dose did not have any significant increase when compared with the drug control (Fig. 2d).

Betulinic acid stimulates immune response via IgG and IgM upregulation 
Given that stimulation of the immune response is a critical factor in malarial parasite clearance from the host cells and as an underlying clinical immunity to malaria, we determined the serum total IgG and IgM levels in mice infected with malarial parasites (susceptible and resistant) but treated with betulinic acid. Our results show that malarial infection significantly $(P<0.001$ and $P<0.01)$ lowers serum levels of IgG in both models, respectively. However, betulinic acid significantly increased lgG level in the resistant $(P<$ $0.01)$ and the susceptible $(P<0.05)$ models (Figs. $3 a$ and $3 b)$. In this study, we did not observe a significant difference between the IgM levels in the normal mice that was not infected with malarial parasite and the infected control. Furthermore, betulinic acid increased $(P<0.05) \operatorname{lgM}$ level in the susceptible model (Fig. 3c) while there was no significant change $(P>0.05)$ in the serum level of IgM in the resistant model (Fig. $3 \mathrm{~d}$ ). It is interesting to note also that while IgG level of the infected control decreased significantly in both models (Figs. $3 a$ and $3 b$ ), we observed an increase in IgM antibody level of the infected control in both models of malarial infection (Figs. 3c and 3d).

\section{Betulinic acid decreases creatine kinase activity and some marker enzymes}

We determined the activities of creatine kinase (CK), gamma glutamyl transferase (GGT), aspartate and alanine amino transferases (AST and ALT, respectively) to determine the extent of the effects of malarial infection on skeletal or cardiac muscle damage and toxicity of the administered dose on liver tissue. Our results show that although, there is no significant difference between CK levels in the normal and infected controls, betulinic acid $(12.5 \mathrm{mg} / \mathrm{kg})$ significantly $(P<0.05)$ decreased CK level in infected mice treated with betulinic acid in the resistant model (Fig. 4a). Although insignificantly $(P>0.05)$, betulinic acid decreased CK level in the susceptible model (Fig. 4b). Liver damage was observed sequel to significant increase in AST (Figs. 4c and 4d), ALT (Figs. 4e and 4f) and GGT (Figs. 4g and 4h) observed in both models. Significantly too, betulinic acid decreased the activities of these enzymes.

\section{Discussion}

Plasmodium malaria, both susceptible and resistant types, have been discovered to be accompanied by inflammation (Clark et al 2006). This disease has been treated with some drugs and promising phytochemicals such as friedelan-3-one and betulinic acid have been used for the treatment of this deadly infectious disease. Cytokines such as tumour necrosis factor alpha (TNFa) and interlukins are essential mechanisms for systemic disease of which malaria is paramount (Clark et al 2006). Although, regulated release of these mediators have been linked with protective effects and inhibition of parasite growth, extensive release of inflammatory cytokines has been linked with pathological conditions in systemic diseases including malarial infection. It is in this regard that we investigated the regulatory role of betulinic acid on inflammatory cytokines and the possible link of its administration to immunomodulatory potentials in malarial treatment using mouse models.

Interlukins (IL-1 $\beta$ and IL- 6 in this study) belong to the pro-inflammatory cytokines that are involved in the process of pathological pain. IL-1 $\beta$ are released by the monocytes and macrophages during infection and inflammation (Zhang and An, 2007). Interlukin $1 \beta$ has been observed to increase during blood stage 
infection of malarial parasites and correlates with disease severity but are expected to decrease after a successful intervention (. Lyke et al 2004). Therefore, a significant decrease in the levels of IL-1 $\beta$ after intervention with betulinic acid indicated a positive response to betulinic acid consequently leading to a decrease in GPI level, a significant inducer of pro-inflammatory cytokines.

In this study, Betulinic acid administration increased interlukin 6 levels. Interlukin 6 is a multipurpose interlukin that serves both as pro-inflammatory and also as an anti-inflammatory myokine. As a pleiotropic cytokine, it plays a central role in host defense because of its immune and hematopoietic properties. Furthermore, evidence from human and animal studies showed that IL- 6 contributes to host defense through the stimulation of acute phase responses, hematopoiesis and immune reactions (Tanaka et al 2014). Furthermore, an increase in the expression and administration of IL-6 is linked with an increase in circulating platelet count (. Kaser et al, 2001), an important factor needed in malarial treatment because thrombocytopenia occurs in malaria-infected patients (Kotepui et al 2014).

Cytokines such as interlukins and tumor necrosis factor alpha (TNFa) perform mechanistic roles in systemic diseases caused by infectious organisms. Previous studies have shown that TNFa acts as homeostatic agent that its excessive production can cause disease condition. In this study, betulinic acid significantly decreased the production of TNFa relative to control. Malarial product such as glycosylphosphatidyl inositol is known to induce TNFa production which at lower concentration inhibits malarial parasite growth but at higher concentrations induce inflammation (Clark 1987). In this study, betulinic acid significantly reduced the TNFa levels to the minimum concentration which can be beneficial to the host. High levels of TNFa is an indication that an individual is susceptible to cerebral malaria (McGuire et al 1994).

The C-reactive protein (CRP) is an important marker of the severity of malarial infection. Previous studies have shown that serum CRP levels is directly proportional to parasite load and complications in malaria and it is a useful marker of malarial severity and inflammation (Hurt et al 1994; Paul et al 2004). Interestingly, betulinic acid administration significantly decreased the level of CRP in both models of malarial infection using mouse models.

Plasmodium parasites impairs the immune system of the host, preventing them from eliciting immune response during infection and this may explain why malarial patients are often susceptible to other infections and fail to respond to several vaccine treatments. Protection against malaria is caused by an increase in serum immunoglobulin $\mathrm{G}(\mathrm{IgG})$ levels as a form of acquired immunity (Doolan et al 2009). Similarly, serum IgM levels significantly increased in the resistant model while there was also an insignificant increase in the susceptible model when mouse malaria was treated with betulinic acid. Previous study has shown that maintenance of IgM response to malaria may have an important role in immunity both for the primary infection and subsequent infections (Boyle et al 2019). We conclude therefore, that IgG and IgM responses are important contributors to naturally-acquired immunity against malaria. 
There is evidence of critical skeletal muscle damage in malarial infection (Davies et al 1999). During this period, serum enzymes such as lactate dehydrogenase, aspartate aminotransferase, alanine aminotransferase and creatine kinase levels are significantly increased. These changes in the levels of these enzymes depend on the severity of the muscle disease and the applied therapy. Circulating creatine kinase increases in severe malaria and it is an important factor in fatal falciparum malaria (Ehrhardt et al 2004). Moreover, some antimalarial drugs have been discovered to have deleterious effects on cardiac and skeletal muscle. Chloroquine (Ikezoe et al 2009), quinine (Silamut et al 1995) and artesunate (Tan et al 2014) caused cardiomyopathy, ventricular fibrillation and proliferation of airway smooth muscle cells in humans, respectively. Apart from multidrug resistance and monotherapy inefficiencies, these are potential reasons for the rejection of these drugs as antimalarials. Interestingly, betulinic acid caused significant decrease in total creatine kinase, a critical index in muscle damage caused by malarial infection.

Malarial infection is associated with significant increase in the serum levels of aspartate and alanine aminotransferases (Al-Salahy et al 2016), showing that malarial infection at the pre-erythrocytic stage causes liver injury. In this study, serum levels of these enzymes increased in both models. Although, artemether-lumefantrine is a drug of choice for clinical cure of multidrug malarial infection, it causes significant liver enzyme abnormalities in aspartate and alanine aminotransferases, though asymptomatic (Pinto et al 2017). Treatment of susceptible and resistant malaria with betulinic acid in mouse model significantly decreased the serum levels of these aminotransferases. Gamma glutamyl transferase (GGT) is a liver membranous enzyme as alkaline phosphatase is (Jarikre et al 2001). The positive correlation between malarial infection and serum increase in GGT level was mitigated significantly by betulinic acid in both models.

In summary, this study has shown that in addition to its antimalarial properties, betulinic acid possesses immunomodulatory and anti-inflammatory potentials needed in the treatment of such infectious disease by lowering the levels of the pro-inflammatory cytokines. Furthermore, responses in IgG and IgM levels are important factors in naturally acquired immunity to malaria and the doses administered in this study does not have toxic effects but rather reduced the serum levels of AST, ALT and GGT which are indicators of liver toxicity.

\section{Abbreviations}

IL: Interlukin

IL-1 $\beta$ : Interlukin one beta

IL-6: Interlukin 6

TNFa: Tumour necrosis factor alpha

IgG: Immunoglobulin G 
IgM: Immunoglobulin M

ALT: Alanine aminotransferase

AST: Aspartate aminotransferase

GGT: Gamma glutamyl transferase

CK: Creatine kinase

CRP: C-reactive protein

\section{Declarations}

\section{Funding}

The authors are the financiers of this study

\section{Conflict of interest/Competing interest}

The authors declare that no conflict of interest exists

\section{Authors' contribution}

JOO conceived this research idea, purified betulinic acid, performed data analysis and wrote the draft manuscript; POO treated the animals and performed assays; 000 read and corrected the manuscript. All authors read and approved the manuscript.

\section{Ethics Approval}

All experiments were performed in accordance with the National Institute of Health guide for the care and use of laboratory animals (NIH Publications No. 8023, revised 1978). All protocols with respect to the care and use of experimental animals as laid down by the institute's guide were strictly followed. Furthermore, ethical approval for this study was obtained from the University of Ibadan Animal Care \& Use Research Ethics Committee (ACUREC).

\section{Consent to participate}

Not Applicable

\section{Consent for publication}

All authors approved the manuscript for publication

\section{References}


Al-Salahy M, Shnawa B, Abed G, Mandour A, Al-Ezzi A (2016) Parasitemia and its relation to hematological parameters and liver function among patients malaria in Abs, Hajjh, Northwest Yemen. Interdiscip Perspect Infect Dis (2016) 5954394. doi: 10.1155/2016/5954394

Boyle MJ, Chan JA, Handayuni I, Reiling L, Feng G, Hilton A, Kurtovic L, Oyong D, Piera KA, Barber BE, William T, Eisen DP, Minigo G, Langer C, Drew DR, de Labastida Rivera F, Amante FH, Williams TN, Kinyanjui S, Marsh K, Doolan DL, Engwerda C, Fowkes FJI, Grigg MJ, Mueller I, McCarthy JS, Anstey NM, Beeson JG (2019) IgM in human immunity to Plasmodium falciparum malaria. Sci. Adv. 5: eaax4489

Braga TM, Rocha L, Chung TY, Oliveira RF, Pinho C, Oliveira A, Morgado J, Cruz A (2020)

Biological activities of Gedunin-A limonoid from meliaceae family. Molecules 25(3): 493.

Clark IA (1987) Cell-mediated immunity in protection and pathology of malaria. Parasitol Today 3:300305.

Clark IA, Budd AC, Alleva LM, Cowden WB (2006) Human malarial disease: a consequence of inflammatory cytokine release. Malaria J. 5: 85.

Davis TM, Supanaranond W, Pukrittayakamee S, Holloway P, Chubb P, White NJ (2000) Progression of skeletal muscle damage during treatment of severe falciparum malaria. Acta Trop 76: 271-276.

Davies TME, Pongponratan E, Supanaranond W, Pukrittayakamee S, Helliwell T, Holloway P, White NJ (1999) Skeletal muscle involvement in falciparum malaria: Biochemical and untrastructural study. Clin Infect Dis. 29: 831-835.

Doolan DL, Dobano C, Baird K (2009) Acquired immunity to malaria. Clin. Microbiol. Rev. 22: 13-36.

Egbubine CO, Adeyemi MM, Habila JD *2020) Isolation and characterization of betulinic acid

from the stem bark of Feretia canthiodes and its antimalarial potential Bulletin of the National

Research centre 44(1). Doi:10.1186/s42269-020-00302-2.

Ehrhardt S, Wichmann D, Hemmer CJ, Burchard GD, Brattig NW (2004) Circulating concentrations of cardiac proteins in complicated and uncomplicated Plasmodium falciparum malaria. Trop Med Int Health. 9: 1099-1103.

Hurt N, Smith T, Tanner M, Mwankusye S, Bordmann G, Weiss NA (1994) Evaluation of C-reactive protein and haptoglobin as malaria episode markers in an area of high transmission in Africa. Trans $\mathrm{R}$ Soc Trop Med Hyg. 88: 182-186. 
Ikezoe K, Furuya H, Arahata H, Nakagawa M, Tateishi T, Fujii N, Kira JI (2009) Amyloid-beta accumulation caused by chloroquine injections precedes ER stress and auto phagosome formation in rat skeletal muscle. Acta Neuropathol. 117: 575-582.

Jarikre AE, Emuveyan EE, Idogun SE (2001) Pitfalls in the interpretation of liver parenchymal and membranous enzyme results in pre-clinical Plasmodium falciparum malaria in the Nigerian environment. Nig J Clin Pract 4:19-21.

Kaser A, Brandacher G, Steurer W (2001) Interlukin-6 stimulates thrombopoiesis through thrombopoietin: role in inflammatory thrombocytosis. Blood 98: 2720-2725.

Kotepui M, Phunphuech B, Phiwklam N, Chupeerach C, Duangmano S (2014) Effect of malarial infection on haematological parameters in population near Thailand-Myanmar border. Malaria J. 13: 218.

Lyke KE, Burges R, Cisoko Y, Sangare I, Dao M, Diarra I, Kone A, Harley R, Plowe CV, Doumbo OK, Sztein MB (2004) Serum levels of inflammatory cytokines, interlukin-1 beta (IL-1beta), IL-6, IL-8, IL-10, tumour necrosis factor alpha, and IL-12 in Malian children with severe Plasmodium falciparum malaria and matched uncomplicated malaria or healthy controls. Infect. Immun. 72 (2004) 5630-5637.

Marrelli MT, Brotto M (2016) The effect of malarial and anti-malarial drugs on skeletal and cardiac muscles. Malaria J. 15: 524.

Mavondo GA, Mkhwananzi BN, Mabandla MV (2016) Pre-infection administration of Asiatic acid retards parasitemia induction in Plasmodium berghei murine malaria infected Sprague-Dawley rats. Malaria J 15: 226.

Mavondo GA, Mkhwanazi BN, Mzingwane ML, Dangarembizi R, Zambuko B, Moyo O, Musiwaro P, Chikuse FF, Rakabopa C, Mpofu T, Mavondo J (2019) Malarial Inflammation-Driven Pathophysiology and Its Attenuation by Triterpene Phytotherapeutics. In: Parasitology and microbiology research. DOI: http://dx.doi.org/10.5772/intechopen.88731.

McGuire W, Hill AV, Allsopp CE, Greenwood BM, Kwiatkowski D (1994) Variation in the TNF-a and interleukin-1 (IL-1) promoter region associated with susceptibility to cerebral malaria. Nature. 371: 497:508.

Miller KD, White NJ, Lott JA, Roberts JM (1989) Biochemical evidence of muscle injury in African children with severe malaria. J Infect Dis 159: 139-142.

Mishra SK, Newton CR (2009) Diagnosis and management of the neurological complications of falciparum malaria. Nat Rev Neurol 5: 189-198.

Noungoue DT, Chaabi M, Ngouela S, Antheaume C, Boyom FF, Gut J, Rosenthal PJ, Lobstein A Tsamo E (2009) Antimalarial compounds from the stem bark of Vismia laurentii Z Naturforsch 64c: 210-214. 
Paul R, Sinha PK, Bhattacharya R, Banerjee AK, Raychaudhuri P, Mondal J (2004) Study of C reactive protein as a prognostic marker in malaria from Eastern India. Adv Biomed Res 1: 41.

Pinto AS, Ruas R, Almeida F, Duro R, Silva A, Abreu C, Sarmento A (2017) Artemether-lumefantrine and liver enzyme abnormalities in non-severe Plasmodium falciparum malaria in returned travelers; a retrospective study with quinine-doxycycline in a portuguese centre. Malaria J. 16: 43. Doi: 10.1186/s12936-017-1698-y

Ryley JF, Peters W (1970) The antimalarial activity of some quinolone esters. Ann Trop Med

Parasit 64: 209-222.

Schofield L, Hackett F (1993) Signal transduction in host cells by a glycosylphosphatidyl inositol toxin of malaria parasites. J Exp Med 177: 145-153.

Silamut K, Hough R, Eggelte T, Pukrittayakamee S, Angus B, White NJ (1995) A simple method for assessing quinine pre-treatment in acute malaria. Trans R Soc Trop Med Hyg. 89: 665-667.

Tachado SD, Gerold P, Mcconville MJ, Baldwin T, Quilici D, Schwarz RT, Schofield L (1996) Glycosylphosphatidyl inositol toxin of Plasmodium induces nitric oxide synthase expressiuon in macrophages and vascular endothelial cells by a protein tyrosine kinase-dependent and prote4in kinase C-dependent signaling pathway. J Immunol. 156: 1897-1907.

Tan SS, Ong B, Cheng C, Ho WE, Tam JK, Stewart AG, Harris T, Wong WS, Tran T (2014) The antimalarial drug artesunate inhibits primary human cultured airway smooth muscle cell proliferation. Am J Respir Cell Mol Biol. 50: 451-458.

Thompson D, Pepys MB, Wood SP (1999) The physiological structure of human C-reactive protein and its complex with phosphocholine. Structure 7: 169-177.

Tanaka T, Narazaki M, Kishimoto T (2014) Interlukin 6 in inflammation, immunity and disease. Cold spring Harb Perspect Biol 6: a016295.

Verlinden BK, Louw A, Birkholtz LM (2016) Resisting resistance: is there a solution for malaria? Exp Opin Drug Dis 29: 1-12.

Zhang JM, An J (2007) Cytokines, inflammation and pain. Int Anesthesiol Clin. 45: 27-37.

\section{Figures}



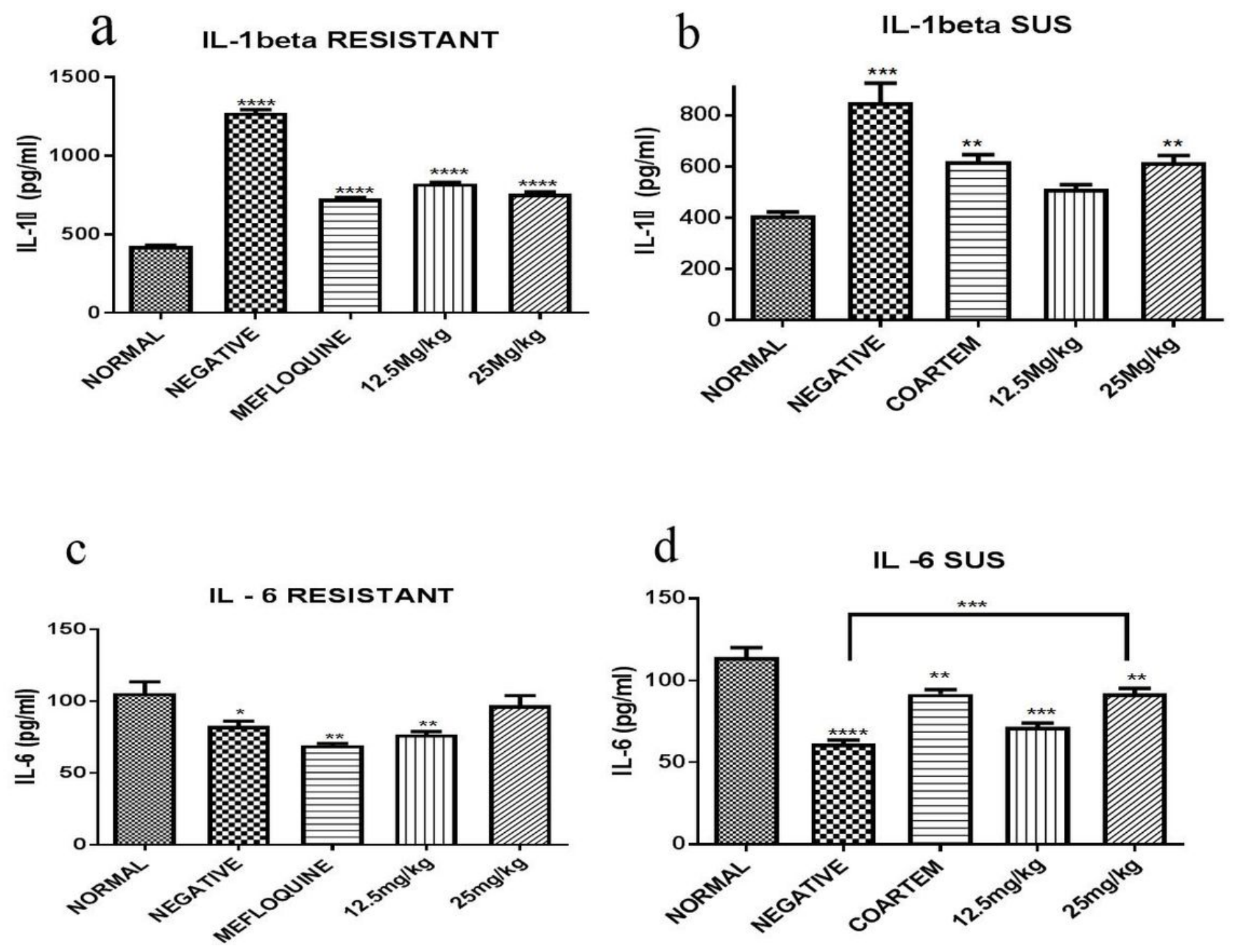

Figure 1

Comparative influence of betulinic acid on the levels of interlukin $1 \beta$ ('a' for resistant and ' $b$ ' for susceptible) and interlukin 6 ('c' for resistant and ' $d$ ' for susceptible) in the serum of mice infected with chloroquine susceptible and resistant strains of Plasmodium berghei. ${ }^{*}=P<0.05 ;{ }^{* *}=P<0.01 ; * \star *=P<0.001$; $\star \star \star \star *=P<0.0001$ treated groups vs normal control. In $1 \mathrm{~d}$, the infected control (negative) was compared with other groups and $25 \mathrm{mg} / \mathrm{kg}$ dose of betulinic acid significantly $(P<0.001)$ increased IL-6. 

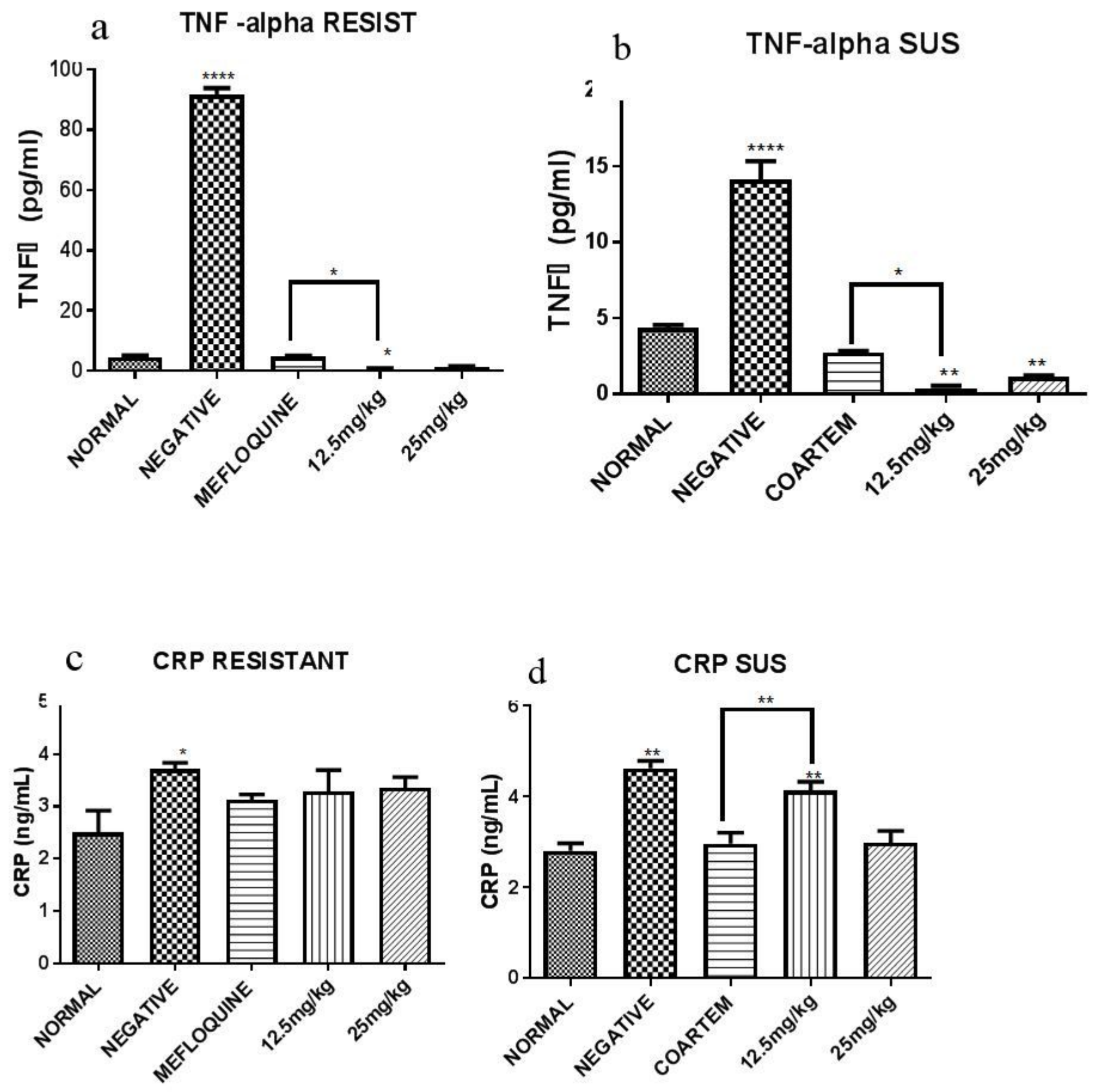

Figure 2

The influence of betulinic acid treatment of malaria on tumour necrosis factor in mice infected with chloroquine susceptible (2a) and resistant (2b) strains of P. berghei and also the effects of such treatment on C-reactive protein in chloroquine susceptible (2c) and resistant models. ${ }^{*}=P<0.05$; $\star *=\mathrm{P}<0.01 ; * \star \star * *=\mathrm{P}<0.0001$. 


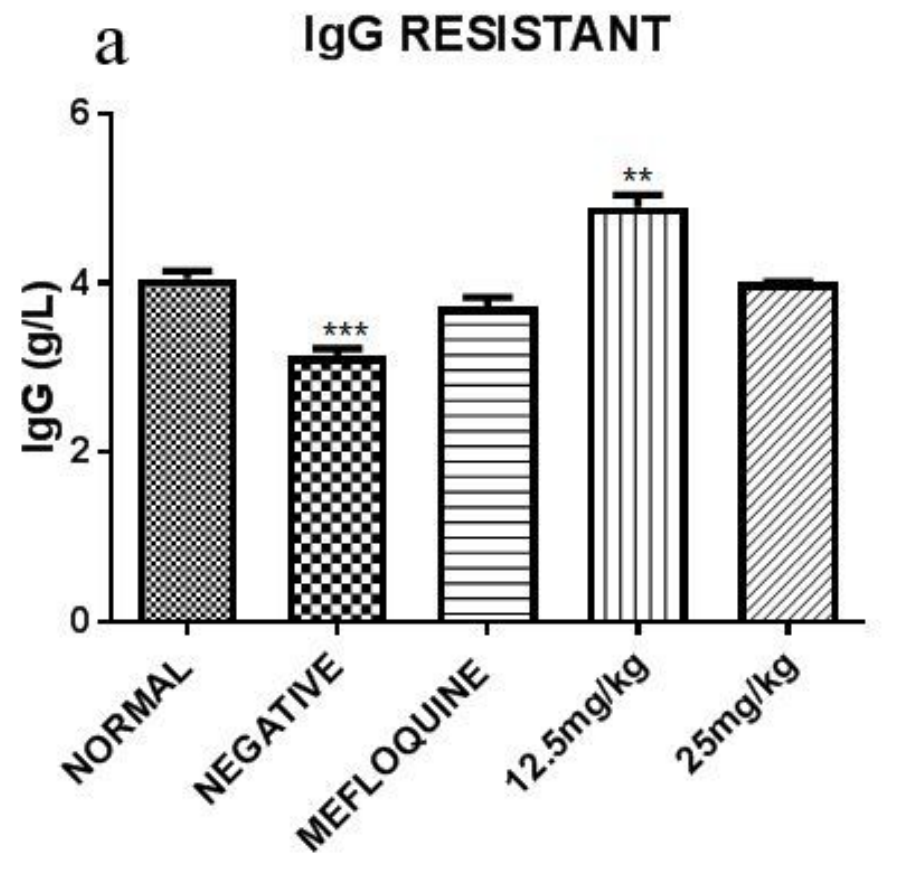

b IgG SUS
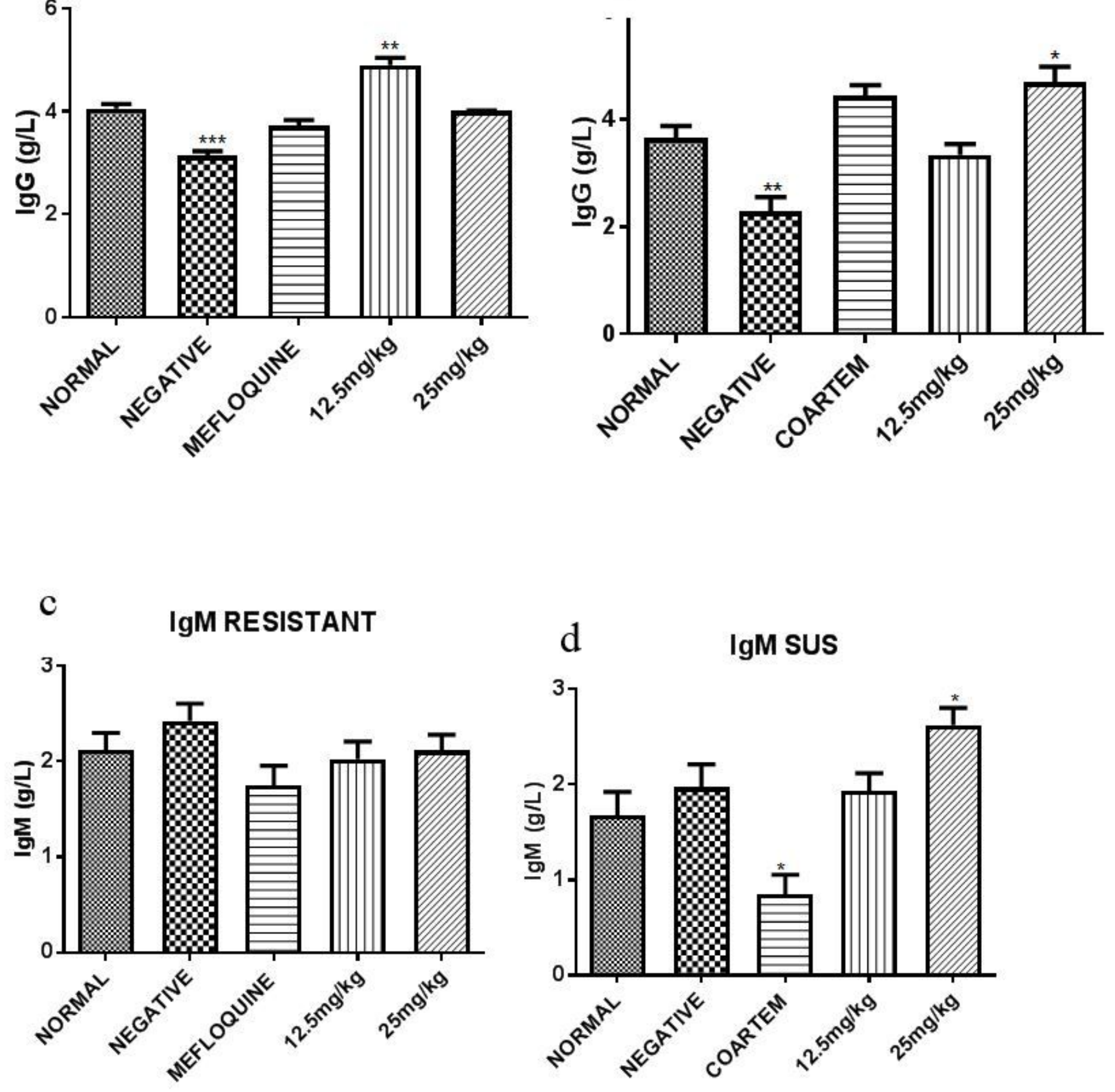

Figure 3

Influence of malarial treatment with betulinic acid on serum immunoglobulins $\mathrm{G}$ ( $3 a$ and $3 \mathrm{~b}$ ) and immunoglobulin $\mathrm{M}(3 \mathrm{c}$ and $3 \mathrm{~d})$ in susceptible and resistant models of malarial infection. ${ }^{*}=P<0.05$; $* *=P<0.01 ; * \star *=P<0.001$ treated groups vs normal control. 

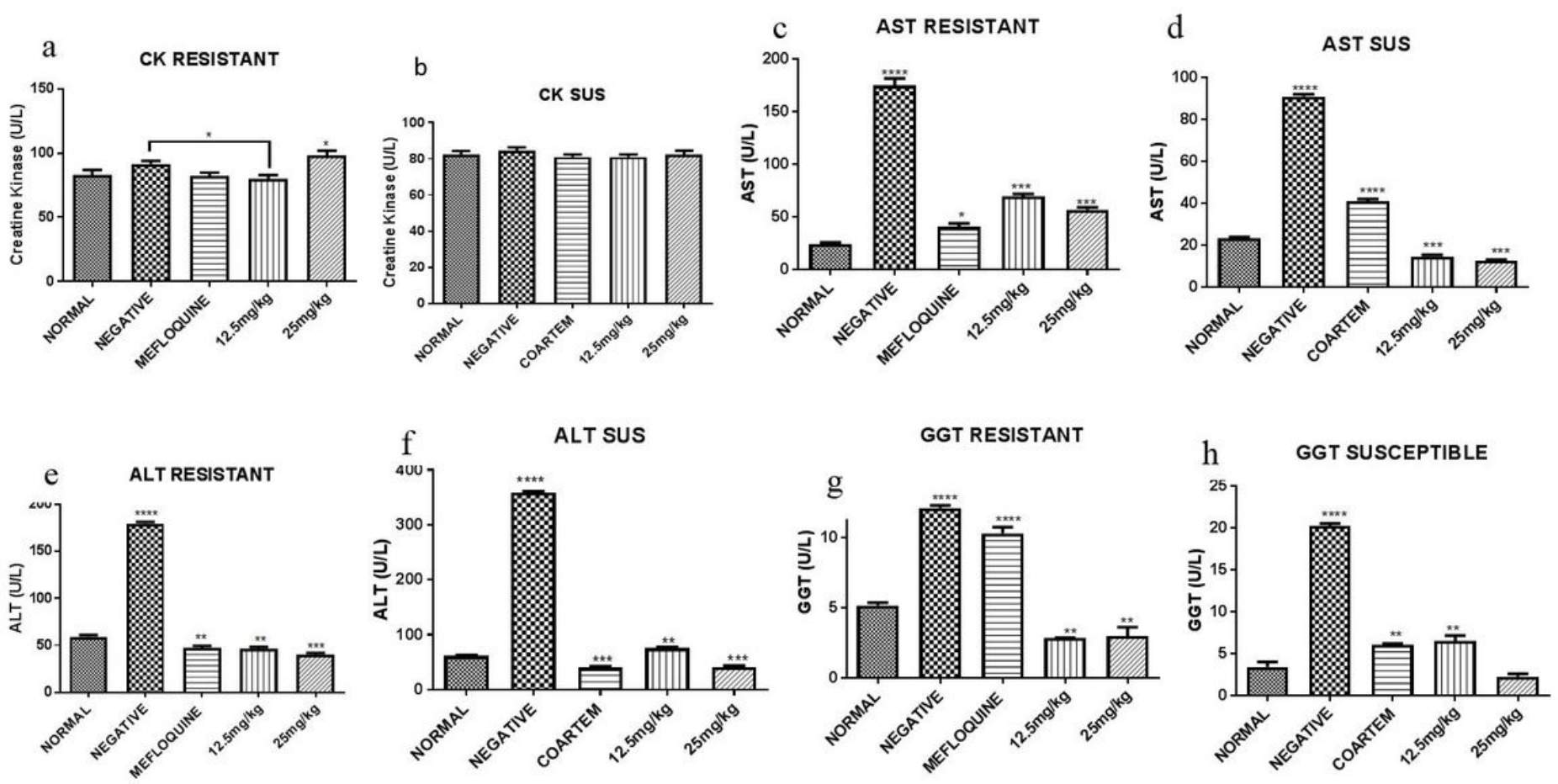

\section{Figure 4}

The protective influence of betulinic acid against skeletal and cardiac muscle damage via the assessment of creatine kinase ( $4 a$ and $4 b$ ) and the toxicity assessment of betulinic acid on liver tissue using aspartate (4c and 4d), alanine aminotransferases (4e and 4f) (AST and ALT) and gamma glutamyl transferase (GGT) (4g and $4 \mathrm{~h}$ ) in chloroquine susceptible and resistant models of malarial infection. $*=P<0.05 ; * \star=P<0.01 ; * \star *=P<0.001 ; * \star \star \star *=P<0.0001$ normal control vs treated control.

\section{Supplementary Files}

This is a list of supplementary files associated with this preprint. Click to download.

- Structureofbetulinicacid.jpg 